\title{
纎維の軸に垂直方向熱伝導率測定
}

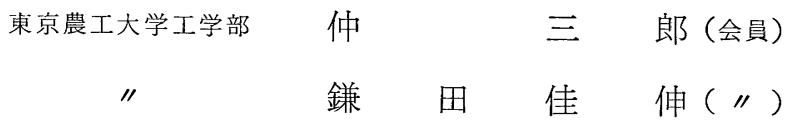

\section{Measurement of the Thermal Conductivity of Fiber Perpendicular to its Axis.}

\section{Saburo Naka and Yoshinobu Kamata,}

\author{
Department of Textiles and Polymer Science, Faculty of Technology, \\ Tokyo University of Agriculture and Technology, Tokyo.
}

\begin{abstract}
An expression for the effective thermal conductivity of fiber assembly formed with many fibers placed in parallel with each other was derived on the basis of two simple models, constructed with fibers surrounded by air and vice versa.

Substituting the effective thermal conductivity measured on polyester fibers at air pressure $10^{-5} \mathrm{~mm}$ and $760 \mathrm{~mm}$ of $\mathrm{Hg}$ into the foregoing expression, we had the thermal conductivity of the fiber perpendicular to its axis.

The theoretical values of the effective thermal conductivity of polyester fabrics estimated by means of the thermal conductivity of the fiber obtained from this work agreed reasonably with that measured by the line heat source methood, the results of the work in reference to this method is in contribution.
\end{abstract}

(Received March 14, 1972)

摘 要

目 的 円筒に密に巻いたマルチフィラメント系の有効熱伝導率を常圧と低圧で測定し，それらの値を使用して 繊維自身の軸に垂直方向熱伝導率をあとめる.

成 果 多数平行に並んだ瀻維束の瀻維に垂直方向の有効熱伝導率を，2つのモデル，すなわち繊維を気体が取 り囲んでいるモデルと気体を瀻維が取り囲んでいるモデルの有効熱伝導率で表わし，ポリエステル緎維について常 圧と低圧で測定して得た有効熱伝導率を上の式に適用して, 繊維自身の軸に垂直方向熱伝導率をむとめた。

(昭和 47 年 3 月 14 日受理) 


\section{1. 緒言}

高分子の熱伝導率については多くの報告があり, 結晶 化度の大きいほど, また重合度の大きいほど熱伝導率が 大きくなり, 分子の配向がよい場合, その方向の熱伝導 率は大きくなるが，それに垂直方向では逆に小さくなる ことが知られている。

瀻維む高分子であるから分子の配向からみて, 軸に垂 直方向，すなわち横方向の熱伝導率は長さ方向のそれよ り小さいととが予想される. しかし高分子の熱伝導率の 測定はほとんど板状試料について行なわれており，繊維 そのあのを直接測定した例がない.

本研究においては，気体をなるべく排除するため，円 柱状ヒーターに繊維を密に巻いてその横熱伝導率を測定 した.

\section{2. 理論}

円柱状ヒーターに䋐維を密に巻付けた場合, 瀻維層内 の輻射と対流が無視できると仮定すると，定常状態にお ける円柱の単位長さ, 単位時間当たりの発熱量を $Q$, 円 柱軸から距離 $r_{1}, r_{2}$ の繊維層内の温度をそれぞれ $v_{1}$, $v_{2}$ とすると，円柱が充分長い場合，繊維層の見掛けの 熱伝導率，すなわち有効熱伝導率 $K e$ はつぎの式で表わ される。

$$
K e=\frac{Q \ln \frac{r_{2}}{r_{1}}}{2 \pi\left(v_{1}-v_{2}\right)}
$$

$K e$ は, 繊維の横熱伝導率 $K_{\perp}$, 空隙を満たす気体の 熱伝導率 $K g$, 繊維の容積比率 $f$ および繊維の配列状態 などによって決まる，したがっててれらの関係がわかれ ば $K e$ を測定して $K_{\perp}$ をあとめるととができる.

繊維層に垂直に熱が流れる場合, 繊維の容積比率 $f$ が 小さく，その接触が無視できるときは，気体が繊維を取 巻いているから，第 1 図のモデル I において熱の流机 垂直な等温面を平面と仮定することにより，その有効熱 伝導率 $K e_{\mathrm{I}}$ は輻射と対流が無視できる場合つぎの式で 表わされる。

$$
K e_{\mathrm{I}}=\left(\frac{1-\sqrt{f}}{K g}+\frac{1}{K_{\perp}+K g\left(\frac{1}{\sqrt{f}}-1\right)}\right)^{-1} \cdots \cdots .
$$

ただし

$$
f=\frac{l^{2}}{L^{2}}
$$

また繊維容積比率が大きくてその接触が無視できない ときは，接触によって繊維が気体を取巻いているから第

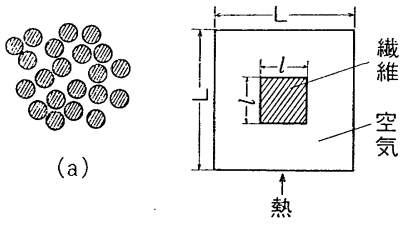

(b)モデル

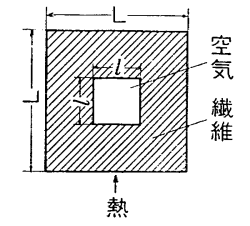

(c)モデル II

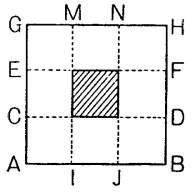

(d)

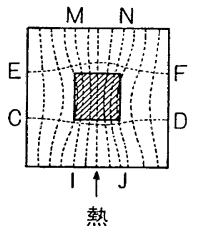

(e)流線と等温面

$K_{\perp}>K_{g}$
（第 1 図） 繊維層の断面とそのモデル

1 図モデルIにおいてその有効熱伝導率 $K e$ I はつぎの 式で表わされる.

$$
K e_{\mathbf{I}}=\left[\frac{1-\sqrt{1-f}}{K_{\perp}}+\frac{1}{K g+K_{\perp}\left(\frac{1}{\sqrt{1-f}}-1\right)}\right)^{-1} \cdots
$$

ただし

$$
f=1-\frac{l^{2}}{L^{2}}
$$

$K e_{\mathrm{I}}$ と $K e_{\mathrm{I}}$ とは $f=0, f=1$ 亿扔いて同じ值を示 し， $0<f<1$ に扔いて $\mathrm{Ke}$ I が $K e_{\mathrm{I}}$ より大きい值を示 す。第 2 図は $K_{\perp} / K g=10$ と仮定した場合の $f$ と $K e_{\mathrm{I}}$, $K e \mathbf{I}$ との関係を示したものである.

円柱に繊維を巻付ける場合は，第1(a)図に示すでと く繊維の密接した部分と空隙の大きい部分とができるか ら，モデル I とモデル II とが混在していると考え，後者 の割合を $n$ とすると, 全体の有効熱伝導率 $K e$ はつぎ

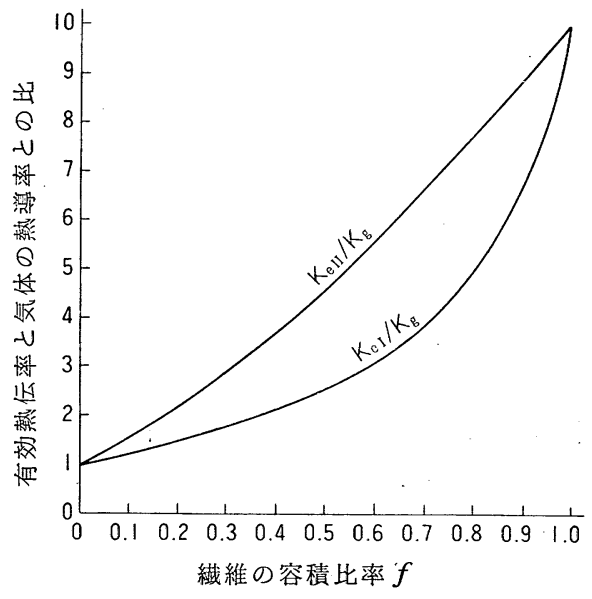

（第 2 図）瀻維の容積比率と各モデルの有効 熱伝導率との関係, $K_{\perp} / K g=10$ 
の式で表わすととができる.

$$
K e=n K e \mathbf{I}+(1-n) K e \mathrm{I}
$$

（2），（3）式を（4）式に代入すると,

$$
\begin{aligned}
K e= & \frac{n}{\frac{1-\sqrt{P}}{K_{\perp}}+\frac{1}{K g+K_{\perp}\left(\frac{1}{\sqrt{P}}-1\right)}} \\
& +\frac{1-n}{\frac{1-\sqrt{f}}{K g}+\frac{1}{K_{\perp}+K g\left(\frac{1}{\sqrt{f}}-1\right)}}
\end{aligned}
$$

ただし

$$
P=1-f
$$

また䋐維層内の空陌の大きさに比し気体分子の平均自 由行程がはるかに大きくなる低圧においては気体の熱伝 導率を無視できるから，その場合の有効熱伝導率を $K e^{\prime}$ とすると（5）式から

$$
K e^{\prime}=\frac{n}{\frac{1-\sqrt{P}}{K_{\perp}}+\frac{1}{K_{\perp}\left(\frac{1}{\sqrt{P}}-1\right)}} \cdot
$$

が得られる.（5），（6）式から

$$
K e=\frac{\left(1-\sqrt{P}+\frac{\sqrt{P}}{1-\sqrt{P}}\right) K e^{\prime}}{1-\sqrt{P}+\frac{1}{\frac{K g}{K_{\perp}}+\frac{1-\sqrt{P}}{\sqrt{P}}}}
$$

$$
+\frac{1-\left(1-\sqrt{P}+\frac{\sqrt{P}}{1-\sqrt{P}}\right) \frac{K e^{\prime}}{K_{\perp}}}{1-\sqrt{f}+\frac{1}{\frac{K_{\perp}}{K g}+\frac{1-\sqrt{f}}{\sqrt{f}}}} \cdot K g
$$

したがって, 熱伝導率既知の常圧気体中での有効熱伝 導率 $K e$ と, 熱伝導率が無視できる低圧気体中での有効 熱伝導率 $K e^{\prime}$ を（1）式を用いて測定すれば，（7） 式により繊維の 横熱伝導率 $K_{\perp}$ をあとめることができ る.

\section{3. 試料と実験装置}

長さ $30 \mathrm{~cm}$, 直径 $2.5 \mathrm{~mm}$ のベークライト棒に $0.18 \mathrm{~m}$ $\mathrm{m}$ のエナメル銅線を密巻きし, それを内径 $3 \mathrm{~mm}$, 外径

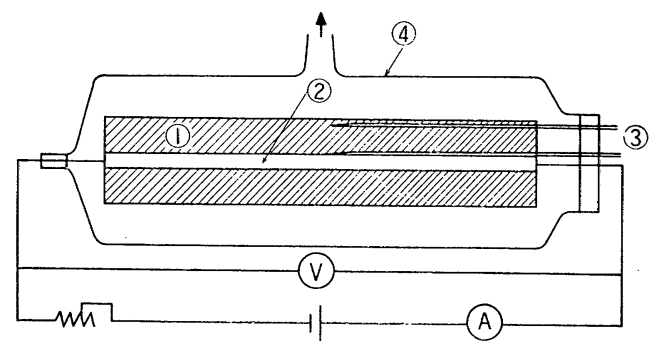

\begin{tabular}{|c|c|c|c|c|c|c|c|}
\hline $\begin{array}{l}\text { 試 料 } \\
\text { No. }\end{array}$ & $\begin{array}{c}\text { 瀻 維 の } \\
\text { 容積比率 } \\
f\end{array}$ & $\begin{array}{c}\text { 温 度 差 } \\
v_{1}-v_{2} \\
\left({ }^{\circ} \mathrm{C}\right)\end{array}$ & $\begin{array}{c}\begin{array}{c}\text { 平均温度 } \\
v_{1}+v_{2}\end{array} \\
2 \\
\left({ }^{\circ} \mathrm{C}\right)\end{array}$ & 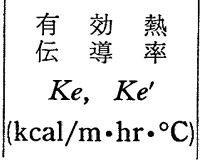 & $\begin{array}{c}\text { 維 纎 } 9 \\
\text { 横熱率 } \\
K_{\perp} \\
\left(\mathrm{kcal} / \mathrm{m} \cdot \mathrm{hr} \cdot{ }^{\circ} \mathrm{C}\right)\end{array}$ & $\begin{array}{l}\text { モデルの } \\
\text { 割 } \\
n\end{array}$ & $\begin{array}{l}\text { ヒーターの } \\
\text { 発 熱 量 } \\
(\mathrm{kcal} / \mathrm{m} \cdot \mathrm{hr})\end{array}$ \\
\hline 1 & 0.71 & $\begin{array}{l}2.8 \\
4.8\end{array}$ & $\begin{array}{l}27.4 \\
33.9\end{array}$ & $\begin{array}{l}0.083 \\
0.037\end{array}$ & 0.13 & 0.46 & $\begin{array}{l}1.60 \\
1.23\end{array}$ \\
\hline 2 & 0.76 & $\begin{array}{l}3.2 \\
3.4\end{array}$ & $\begin{array}{l}29.0 \\
28.8\end{array}$ & $\begin{array}{l}0.099 \\
0.066\end{array}$ & 0.14 & 0.72 & $\begin{array}{l}1.91 \\
1.34\end{array}$ \\
\hline 3 & 0.76 & $\begin{array}{l}3.0 \\
2.8\end{array}$ & $\begin{array}{l}30.3 \\
34.0\end{array}$ & $\begin{array}{l}0.101 \\
0.066\end{array}$ & 0.14 & 0.70 & $\begin{array}{l}2.03 \\
1.22\end{array}$ \\
\hline 4 & 0.77 & $\begin{array}{l}3.4 \\
3.6\end{array}$ & $\begin{array}{l}26.9 \\
30.8\end{array}$ & $\begin{array}{l}0.098 \\
0.057\end{array}$ & 0.13 & 0.61 & $\begin{array}{l}2.07 \\
1.26\end{array}$ \\
\hline 5 & 0.78 & $\begin{array}{l}3.0 \\
2.8\end{array}$ & $\begin{array}{l}30.6 \\
33.2\end{array}$ & $\begin{array}{l}0.101 \\
0.070\end{array}$ & 0.13 & 0.76 & $\begin{array}{l}2.03 \\
1.33\end{array}$ \\
\hline 6 & 0.78 & $\begin{array}{l}2.9 \\
2.4\end{array}$ & $\begin{array}{l}29.0 \\
30.0\end{array}$ & $\begin{array}{l}0.108 \\
0.082\end{array}$ & 0.14 & 0.83 & $\begin{array}{l}2.00 \\
1.27\end{array}$ \\
\hline 7 & 0.79 & $\begin{array}{l}3.3 \\
2.9\end{array}$ & $\begin{array}{l}28.5 \\
31.4\end{array}$ & $\begin{array}{l}0.108 \\
0.078\end{array}$ & 0.14 & 0.78 & $\begin{array}{l}2.05 \\
1.28\end{array}$ \\
\hline
\end{tabular}
(1) 試料
(2) ヒータ-
(3) クロメル・アルメル熱電対
(4) ガラス管

（第 3 図）繊維の横熱伝導率測定装置

（第 1 表）実 験 結 果

注）上段は常圧，下段は $10^{-5} \mathrm{mmHg}$ における值， $v_{1} 、 v_{2}$ はそれぞれ $r_{1}, r_{2}$ における温度 
$4 \mathrm{~mm}$ の銅パイプに挿入したむのをヒーターとし，パイ プの外側に 繊維を巻付け, 銅パイプの表面 $r_{1}=2 \mathrm{~mm}$ と繊維層内の $r_{2}=5 \mathrm{~mm}$ ぐらいの位置に, $0.1 \mathrm{~mm}$ のク ロメル・アルメル熱電対をセットする，それらを第 3 図 に示すでとくガラス管の中に封入し, 約 $12 \mathrm{hr}$ 油拡散ポ ンプで圧力を $10^{-5} \mathrm{~m} \mathrm{~m} \mathrm{Hg}$ に下げて後加熱を始め, 7, $8 \mathrm{hr}$ で温度が定常に達したとき有効熱伝導率 $K e^{\prime}$ を測 定し, 引続き乾燥空気を入れ，3，4 hr で定常に達し たとき有効熱伝導率 $K e$ を測定した。

また試料としてはポリエステル $50 \mathrm{~d} / 24 \mathrm{f}$ を使用した。

\section{4. 実験結果と考察}

実験結果を第 1 表（前ページ）に示す．モデルの割合 $n$ は, 得られた $K_{\perp}$ を使用して $(6)$ 式で計算してもと めた。

\section{1 繊維層内の気体の熱伝導率}

繊維層内の気体の熱伝導率を $K g^{\prime}$ ，自由気体のそれを $K g$ ，繊維層内で気体分子が 繊維に衝突するときの平均 自由行程を $L_{f}$ ，自由気体のそれを $L g$ とするとつぎの 式が成立する。

$$
\begin{aligned}
& K g^{\prime}=K g \frac{L_{f}}{L_{f}+L g} \\
& L_{f}=\frac{\pi d}{4 f}
\end{aligned}
$$

ただし $d$ は繊維の直径である．本実験に使用した繊維の 直径は約 $0.015 \mathrm{~mm}$ であるから， $L_{f} \doteqdot 0.016 \mathrm{~mm}$ とな る.また $L g$ の值は圧力 $10^{-5} \mathrm{~m} \mathrm{~m} \mathrm{Hg}$ 亿扔いて約 $7 \times 10^{3}$ $\mathrm{mm}$ であるから $\mathrm{Kg}^{\prime}$ の值は約 $2 \times 10^{-6} \cdot \mathrm{Kg}$ となり,

(6) 式の成立するてとがわかる. 常圧においては $L g$ の值が約 $10^{-4} \mathrm{~mm}$ であるから $L_{f}$ に比し無視でき，（8） 式により $K g^{\prime} \doteqdot K g$ となる.

\section{2 輻射による伝熱}

2 枚の平行平板の温度差が小さい場合, 両平板間の輻 射伝熱量 $q_{r}$ と空気層を伝導で流れる熱量 $q_{c}$ との比は, 両平板を黒体とするとつぎの式で表わされる.

$$
\frac{q_{r}}{q_{c}}=\frac{0.195}{K g}\left(\frac{T m}{100}\right)^{3} d
$$

ただし，

\section{$d:$ 両平板の距離 $(m)$}

$T m:$ 両平板の平均温度 $\left({ }^{\circ} \mathrm{K}\right)$

繊維層内の輻射面間の距離は繊維直径ぐらいと考えら れるから, 繊維を黒体と仮定して, 繊維間の輻射熱を, 間隔 $0.015 \mathrm{~mm}$ の 2 枚の黒体の平行平板間の輻射伝熱で 近似できると考えると， $T m=300^{\circ} \mathrm{K}$ の場合は $q_{r} / q_{c} \doteqdot$ $3 \times 10^{-3}$ となり，輻射伝熱の無視できるととがわかる.

\section{3 刘流の影響}

空気中で測定する場合, 周囲の空気の対流のためヒー タ一軸から同一距離の温度が一様にならないことが考え られる。それを調べるために, 繊維層内の $r=4 \mathrm{~mm} の$ 位置において上下左右に 4 本の熱電対をセットし，その 上にさらに繊維を厚さ約 $2 \mathrm{~mm}$ 巻き, $90^{\circ}$ ずつ回転して 定常状態に扔ける各位置の温度を測定してその平均值と してつぎの值が得られた。

$$
\begin{aligned}
& \text { 上: } 21.7^{\circ} \mathrm{C} \\
& \text { 下: } 21.8^{\circ} \mathrm{C} \\
& \text { 右: } 21.7^{\circ} \mathrm{C} \\
& \text { 左: } 21.7^{\circ} \mathrm{C}
\end{aligned}
$$

あし対流が起とれば下の温度は低く，上の温度が高くな るはずであるからての場合対流の影響のないととがわか る. またとのととは繊維層内の対流も無視できるととが わかるままたてのととは繊維層内の対流も無視できると とを示している.

\section{4 モデルの妥当性}

（2）式は熱の流れに垂直な等温面を平面と仮定して 導いた式である.すなわち第 1 (d)図において, $A B, C D$, $E G, G H$ 面を等温面と仮定した. しかしあし $A B$ 面と $G H$ 面を等温面と仮定し, 熱は繊維軸に垂直方向のみに 流れ，それに直角方向に温度勾配があってもそれによる 熱移動は無視できると仮定すると, 直線 $I M, J N$ を流 線と考えるととにより $\mathrm{Ke}$ Iは（2）式の代わりにつぎの 式で表わされる。

$$
K e_{\mathrm{I}}=K g(1-\sqrt{f})+\frac{1}{\frac{1}{K_{\perp}}+\frac{1}{K g}\left(\frac{1}{\sqrt{f}}-1\right)} .
$$

実際には， $K_{\perp}>K g$ の場合，流線と等温面は第 1 図 $e$ に示すごとく曲線あるいは曲面になる。

渡辺は電気槽による実験結果と（2）式による計算結 果を比較し, 繊維の容積比率 0.451 の場合実験值は 0.074 $\mathrm{kcal} / \mathrm{m} \cdot \mathrm{hr} \cdot{ }^{\circ} \mathrm{C}$, 計算值は $0,071 \mathrm{kcal} / \mathrm{m} \cdot \mathrm{hr} \cdot{ }^{\circ} \mathrm{C}$ となった と報告している。この容積比率は筆者らの使用した值 0.7 〜0.8に比して小さいから瀻維の接触は少ないが，（2） 式はそれを無視しているから計算值が実験值より小さく なるのは当然である．乙れを(11) 式で計算すると 0.058 $\mathrm{kcal} / \mathrm{m} \cdot \mathrm{hr} \cdot{ }^{\circ} \mathrm{C}$ となり, 実験值に比し非常に小さくなる. てれらのととを考慮して本研究においては（2）式を採 用した。

つぎに（2），（3）式で表わされる1次元モデルの 有効熱伝導率が (1) 式に適用できるかどうかを考えて みる。 


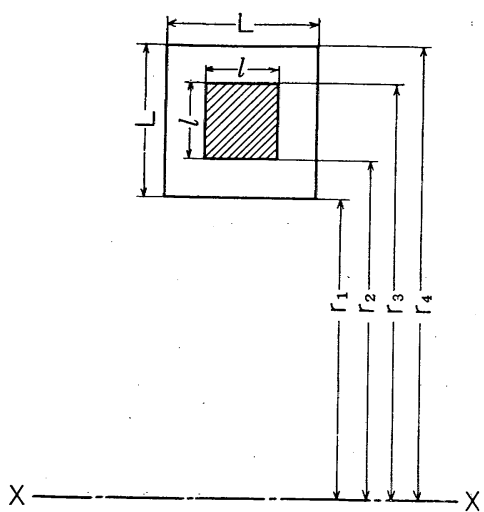

（第 4 図）円筒状繊維層のモデル

第 4 図はヒータ一軸 $X-X$ 加ら半径 $r_{1}$ の位置に, 断 面が第 1 図モデル I と同じリング状のモデルが存在する 場合を示している. 半径 $r_{1}, r_{2}, r_{3}, r_{4}$ の位置の温度 をそれぞれ $v_{1}, v_{2}, v_{3}, r_{4}$ とし，ヒ一タ一の単位長 さ，単位時間当りの発熱量を $Q$ とすると，定常状態に おけるこのモデル リングを通して単位時間に流れる熱 量は式

$$
\begin{aligned}
Q \cdot L & =2 \pi K g \frac{v_{1}-v_{2}}{\ln \frac{r_{2}}{r_{1}}} \cdot L \\
& =2 \pi\left\{K g(L-l)+K_{\perp} l\right\} \frac{v_{2}-v_{3}}{\ln \frac{r_{3}}{r_{2}}} \\
& =2 \pi K g \frac{v_{3}-v_{4}}{\ln \frac{r_{4}}{r_{3}}} \cdot L
\end{aligned}
$$

で表わされ，またリング全体の有効熱伝導率を $K e$ とす ると $Q \cdot L$ はまた式

$$
Q \cdot L=2 \pi K e \frac{v_{1}-v_{4}}{\ln \frac{r_{4}}{r_{1}}} \cdot L
$$

で表わされるから，これらの式からつぎの式が得られ る.

$$
\frac{1}{K e}=\frac{1}{K g}+\left\{\frac{L}{K_{\perp} l+K g(L-l)}-\frac{1}{K g}\right\} \frac{\ln \frac{r_{3}}{r_{2}}}{\ln \frac{r_{4}}{r_{1}}}
$$

しかるに $r_{1}, r_{2}$ などに比し $l, L$ は極めて小さいから 式

$$
\frac{\ln \frac{r_{3}}{r_{2}}}{\ln \frac{r_{4}}{r_{1}}}=\frac{\ln \left(1+\frac{l}{r_{2}}\right)}{\ln \left(1+\frac{L}{r_{1}}\right)}=\frac{\frac{l}{r_{2}}-\frac{1}{2}\left(\frac{l}{r_{2}}\right)^{2}+\cdots}{\frac{L}{r_{1}}-\frac{1}{2}\left(\frac{L}{r_{1}}\right)^{2}+\cdots}=\frac{l}{L}
$$

が得られ，乙の式を（12）式に代入して式

$$
K e=\left[\frac{1-\sqrt{f}}{K g}+\frac{1}{K_{\perp}+K g\left(\frac{1}{\sqrt{f}}-1\right)}\right]^{-1}
$$

すなわち（2）式が得られる.（3）式むまったく同様 であって, 繊維が細くて $l, L$ が $r_{1}$ に比しでく小さい ときは 1 次元モデルを適用できることがわかる.

\section{5 実験結果の織物への適用}

タフタのように糸のプリンプの小さい織物の熱伝導率 は，繊維が一様に分布するたて糸之よて系の繊維層の 熱伝導率で近似的に表わすととができると考えると，

(2) 式の $K e_{\mathbf{I}}$ よりあ大きく, (3) 式の $K e_{\mathbf{I}}$ よりあ 小さくなるはずである。第 5 図は本実験に使用したポリ

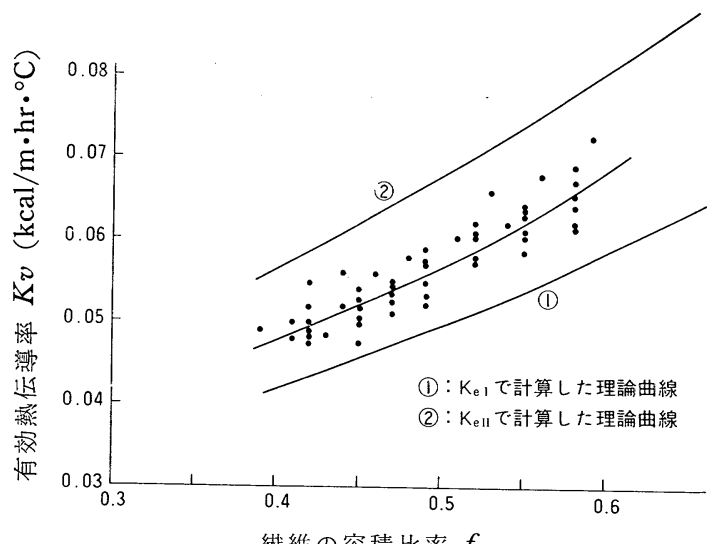

繊維の容積比率 $f$

（第 5 図） ポリエステル・タフタの有効熱伝導率 $\left(20^{\circ} \mathrm{C}, 65 \% \mathrm{R} \mathrm{H}\right)$

エステル マルチ フィラメント系 $50 \mathrm{~d} / 24 \mathrm{f}$ たて糸と よて系に使用したタフタ（たて系密度 40.5 本 $/ \mathrm{cm}$, よと 系密度 36.5 本 $/ \mathrm{cm}$ ) について, 線熱源法により湘定した 結果である。曲線(1)，(2)はそれぞれ（2），（3）式で 計算した理論曲線で, いずれも $K_{\perp}$ の值として第 1 表 から $0.14 \mathrm{kcal} / \mathrm{m} \cdot \mathrm{hr} \cdot{ }^{\circ} \mathrm{C}$ を使用した. 繊維の容積比率 $f$ の小さいときは，曲線(1)近づき， $f$ が大きくなると曲 線(2)近い值を示すはずであるが, 織物の場合密度を大 きく変化させるととが困難であるため $f$ の範囲が狭く, 実験値を用いて最小二乗法でもとめた 2 次曲線が示すで とくあまり明瞭ではない.しかし実験值は曲線(1)と(2)の あいだに分布し，理論值の計算に用いた $K \perp$ の值が抒お むね妥当であるてとを示している.

\section{5. 結 論}

繊維束の有効熱伝導率は, 内部の気体の影響を受ける ことが大きく, 繊維の容積比率が小さいときは, 第 2 図 の $K e_{\mathrm{I}}$ の曲線でわかるごとく, 気体の熱伝導率に近い 
值を示し, 繊維自身の熱伝導率はほとんど影響しなくな る.したがって繊維束を利用して䋐維の横熱伝導率を測 定するためには，絾維の容積比率 $f$ をるべく大きくす るととが必要であり, 本実験に扔いては, 円筒に巻くて

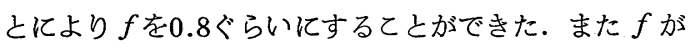
大きくなると繊維の接触部を流れる熱が多くなるるが, てれは低圧で測定するととにより知るととができる.

このようにポリエステル繊維のような疎水性繊維の横 熱伝導率はての方法で測定するてとができるが, 親水性 繊維については, 完全に乾燥して円筒に巻くことが困難 であるため低圧において繊維の容積比率が变化するおそ
れがあり, ての点についてさらに検討する必要がある. おわりに本研究のため試科の提供をうけた東洋紡績株 式会社に謝意を表する.

\section{文献}

1) K. Eiermann ; Kolloid-Z., 180, 163(1962)

2) K. H. Hellwege, J. Hennig, W. Knappe; KolloidZ., 188, 121(1963)

3 ）渡辺; 衛生工業協会誌, 30,77(1956)

4) J. D. Verschoor, P. Greebler, N. J. Manville ; Trans. of A.S.M.E., 961(1952-8)

5 ) 渡辺; 保温保冷工学, p. 134,1960 , 朝倉書店

6) 仲, 本村, 鎌田; 織機誌, 26, T 34 (1973) 